\title{
PIÉROLA NARVARTE, Gemma, Mujer e ideología en la dictadura fran- quista. Navarra (1939-1960), Pamiela, Arre, 2018, 349 pp.
}

Los cuarenta años de dictadura franquista en Navarra supusieron un periodo muy negativo en el territorio. Existen muchas investigaciones en torno a la represión requeté-falangista tras el alzamiento el 19 de julio de 1936, tanto en los años bélicos como en la posterior dictadura. Una represión que en Navarra costó la vida a más de 3.000 personas pero que fueron muchas miles de personas más las que sufrieron diferentes tipos de represión y en grados diversos. Todo ello, recordemos, en una provincia sin frente de guerra y que cayó desde el inicio del lado sublevado. Se ha avanzado mucho en la investigación sobre la represión franquista y, gracias a ello, cada vez el conocimiento es mayor.

Sin embargo se desconocen muchas y muy variadas cuestiones de los años de la dictadura en Navarra. Pese a los grandes avances historiográficos que se han producido, queda aún mucho por investigar. Y queda aún más si de lo que se trata es de conocer la historia de las mujeres en Navarra durante el franquismo. Una historia relegada, arrinconada y silenciada que la autora rescata para poder comprender mejor la sociedad y el ideario franquista en Navarra. Si bien es cierto que en los últimos años hemos asistido a una proliferación de estudios acerca de las mujeres en la historia, y más concretamente de las mujeres navarras, es necesario señalar que hasta no hace mucho existía un auténtico páramo en este sentido. En Navarra, el estudio de Gemma Piérola se puede considerar como pionero en este sentido, un trabajo fruto de su tesis doctoral defendida a finales del año 2011. Han pasado siete largos años para que este novedoso estudio vea la luz en una publicación que recupera a las mujeres y su protagonismo en la historia.

En el tiempo transcurrido desde la defensa de la tesis, siendo esta publicación que se reseña una versión resumida de aquella, han aparecido diversos estudios sobre las mujeres durante la dictadura que complementan la investigación de la autora. Esto otorga más valor si cabe al estudio de Piérola, ya que fue una precursora en este campo. Como toda investigación, propone, además, más ámbitos para estudios futuros de los que se presentan en el libro. La autora pone el foco en un segmento de la población que históricamente ha sido ocultado por la historiografía, no solo local sino también nacional e internacional. Esto, a pesar de ser conocido, no está de más recordarlo ya que existe un gran déficit en este sentido. El libro de Gemma Piérola viene a cubrir un poco ese gran vacío existente.

La investigación llevada a cabo por Piérola se centra en el análisis que tuvo la evolución de las mentalidades femenina y masculina durante la posguerra en Navarra. Una posguerra en donde se impusieron unos valores tanto socioculturales como religiosos que marcaron el devenir de la vida pública y privada de las mujeres navarras. Donde se mezclaba lo civil con lo religioso y se impuso a las mujeres un rol en la edificación del Estado franquista. Ese rol de las mujeres du- 
rante el franquismo estaba estructurado en torno a la familia patriarcal como base moral, social, política y religiosa de un régimen totalitario que intentó controlar todos los resortes de la vida de las personas, especialmente de las mujeres.

El control del rol de las mujeres se realizaba desde diferentes ámbitos. Estaba la represión mediante multas, sanciones o castigos corporales. Pero también la Iglesia, los medios de comunicación o las diferentes asociaciones femeninas ligadas a la dictadura. Estas cuestiones son abordadas por la autora de forma nítida. Explica la función de la Iglesia católica tanto en el control social como en la imposición de una doctrina moral a seguir. Cuestiones que se reflejaban en el día a día de las mujeres, que debían guardar el decoro que se les imponía absteniéndose de prácticas de ocio que no obtuviesen el visto bueno de las autoridades civiles y eclesiásticas. De una propaganda comercial que situaba a la mujer en un segundo plano social, emplazándola al ámbito familiar y al hogar, supeditada al marido, al padre o a cualquier otro varón de la familia. Una publicidad que ejercía de instrumento político con tanta precisión, o incluso mayor, que cualquier adoctrinamiento tradicional. Y acompasado a todo ello las diversas organizaciones femeninas del régimen: la Sección Femenina de Falange y las margaritas carlistas, las cuales tuvieron unas relaciones políticas difíciles con preminencia de las segundas en el territorio navarro. Todo ello se expone en el libro con una forma muy personal característica de la autora pero, a su vez, con un rigor científico absoluto.

El estudio llevado a cabo por Gemma Piérola se sustenta en una amplia base documental, con más de una quincena de archivos consultados, casi una treintena de entrevistas realizadas a mujeres de diversa índole y una completísima bibliografía. Se trata, en definitiva, de un importante estudio sobre un apartado de nuestra historia que ahora comienza a tener, gracias a la autora, la categoría que merece. No es, ni pretende serlo, un estudio definitivo ya que, tal y como señala la autora, existen vacíos que completar en futuras investigaciones. Se trata, en definitiva, de un primer paso, muy sólido, para avanzar en la recuperación de la historia reciente de las mujeres en Navarra.

Mikel Bueno 